\title{
Early Vesico-Ureteral Reflux following Conus Medullaris Injury: Case Report
}

P. Dudognon, Ph.D., C. Labrousse, Ph.D., M. Lubeau, M.D., P. Carné, M.D., M. Rabiller, M.D. and J. M. Boulesteix, M.D.

Service de Rééducation Fonctionnelle (Pr. C. Labrousse), Centre Hospitalier Universitaire, 87042 Limoges, France

\section{Summary}

The authors describe severe vesico-ureteral reflux and simultaneous renal insufficiency which occurred after a spinal cord injury to the conus medullaris. They point out the misleading character of these injuries when there are only minimal neurological signs in the trunk and limbs. The main clinical consequence may be an isolated neuropathic bladder which, if not detected, delays treatment. Additionally, they underline the role of mixed bladder and sphincter lesions in the development of renal insufficiency; also the role of increased intravesical pressure during filling and emptying with bilateral vesico-ureteral reflux.

Key words: Conus medullaris injury; Isolated neuropathic bladder; Vesicoureteral reflux; Renal insufficiency.

\section{Introduction}

The occurrence of a vesico-ureteral reflux during the development of a neuropathic bladder is a severe complication. Its frequency varies between 9 and $25 \%$ according to the literature (Leriche et al., 1983).

This paper describes vesico-ureteral reflux which occurred after spinal cord injury to the conus medullaris. The unusual character of this clinical case includes the early appearance of renal insufficiency and, above all, the misleading character of the neurological examination of the lower limbs since this patient had no signs of paraplegia.

\section{Case Report}

A 48 year old male was admitted to the Centre Hospitalier Universitaire on 16 May 1984 , with a compression fracture of the first lumbar vertebrae following a fall from a ladder. Initial clinical examination revealed no motor or sensory deficits in the lower limbs, but he had urinary retention, faecal incontinence, and perianal hypo-aesthesia. A urinary catheter was inserted. The fracture was internally fixed using Roy-Camille plates; a tear of the dura mater was noted. 
On the 4th day the urinary catheter was removed but the patient still had retention of urine. The bladder was recatheterized for an additional 24 hours at which time bladder emptying was judged to be sufficient to permit the patient's discharge.

Six months later, he was admitted to the Service of Functional Re-education complaining of incomplete micturition (residual urine volume between 50 and $600 \mathrm{ml}$ ). Urination was only possible with forced abdominal pressure.

There was some urinary incontinence during physical activity, inability to urinate when the need arose and failure of the external sphincter after bladder overfilling aggravated by the sitting position. Sensory awareness of the bladder filling and voiding was clearly diminished.

The same sensory deficits were observed concerning anorectal function and the patient complained of slight faecal incontinence when passing gas. Sexual problems were severe, as since the accident erection and ejaculation were impossible.

Neurological examination revealed few anomalies in the lower limbs-only slight weakness of the sural triceps $(3+)$ and toe flexors $(3+$ to $4+)$ on the left side. Walking was normal. Bilateral hypoesthesia was observed over S2 (more pronounced on the left side) as well as slight hypo-aethesia over the S1 area. The right patellar reflex was depressed and the ankle reflexes were absent. The plantar reflexes were not extensor.

The neurological examination of the perianal region showed complete anesthesia of the left buttock, and hypo-aethesia over S3, S4 and S5 on the right side, arreflexia, hypotonia and absence of tonic contraction of the anal sphincter after sudden removal at the finger, and complete loss of voluntary anal control.

Intravenous urography (I.V.U.) revealed a marked delay of renal secretion of both kidneys and ureterohydronephrosis with dilatation of both upper urinary tracts, which were only completely visualized 75 minutes following injection of the contrast medium (Fig. 1).

During micturition the bladder neck opened normally. The proximal urethra filled but the external sphincter area was narrowed, suggesting a functional obstruction such as hypertonia or dyssynergia of the external sphincter.

Retrograde urethrocystography was performed under optimal physiological conditions and showed a pronounced bilateral vesico-ureteral reflux (Fig. 2).

Serum electrolyte studies revealed an organic renal insufficiency with a serum creatinine of $250 \mu \mathrm{mol} / 1$, blood urea between $9,7-11,6 \mathrm{mmol} / \mathrm{l}$ and a decrease in creatinine clearance to $42 \mathrm{ml} / \mathrm{min}$. At the time of trauma initial tests had shown normal renal function.

\section{Urodynamic Studies}

The first gas cystometrogram (Disa 21 G01 cystograph), performed on 26 November 1984, revealed an abnormality with the desire to void appearing only after 340 $\mathrm{ml}$ of gas had been instilled into the bladder. At that point intravesical pressure rose sharply, indicating a strong prolonged and uninhibited bladder contraction. This increase in pressure did not initiate voiding even with additional abdominal pressure or by percussion. A second study 15 days later, gave different results: the intravesical pressure rose progressively from 10 to $70 \mathrm{~cm}$ of water and the compliance was low (less than 5). 


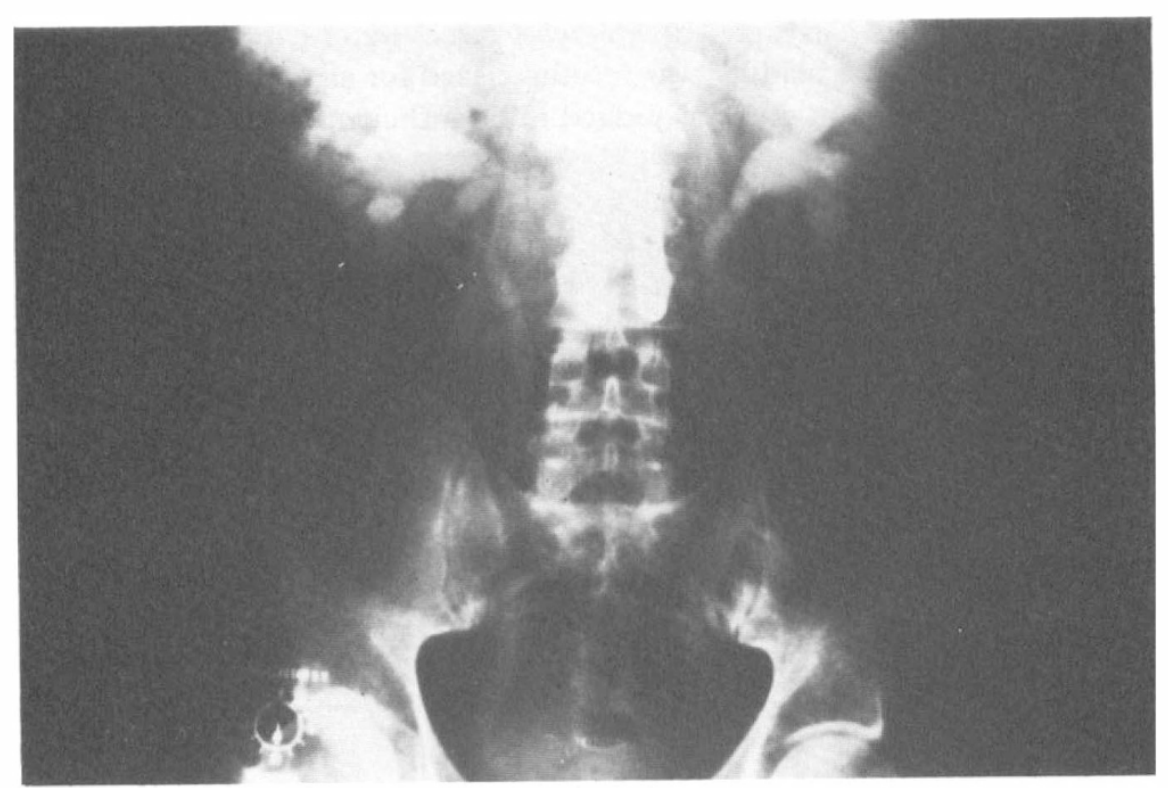

Figure 1. Intravenous urography $\left(30^{\prime}\right)$. Ureterohydronephrosis with dilatation of both upper urinary tracts.

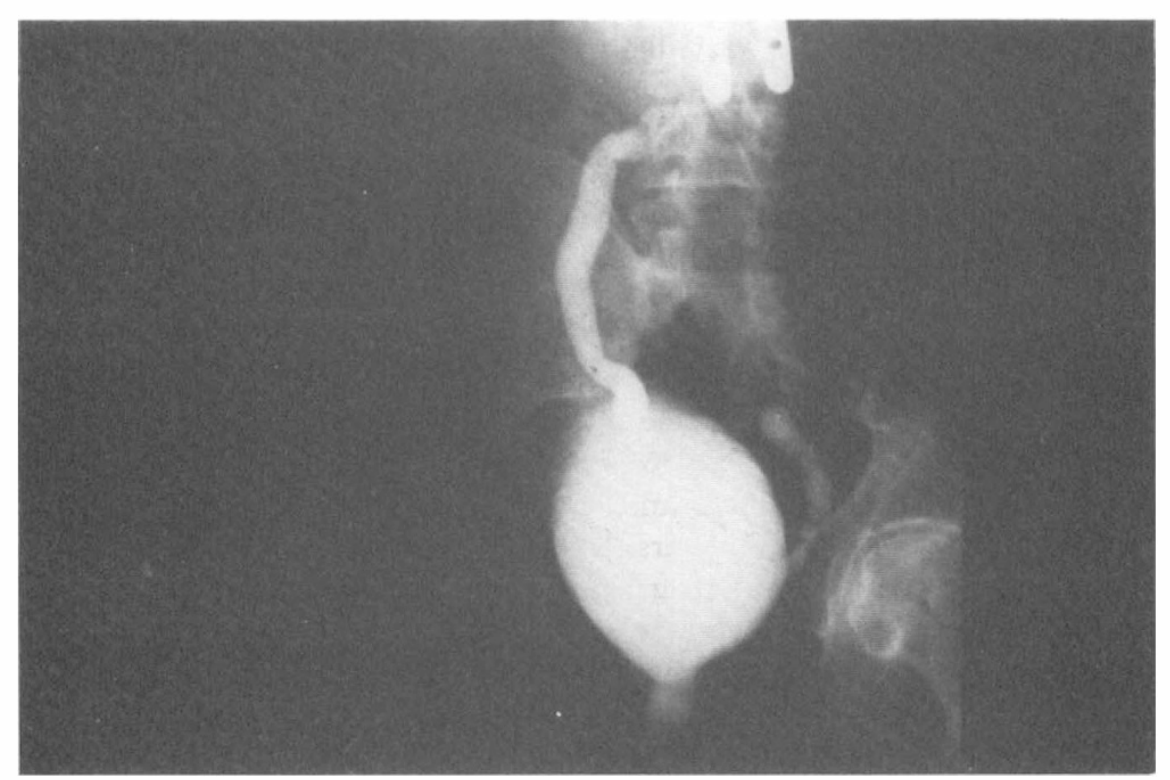

Figure 2. Retrograde urethrocystography, micturition film. Pronounced bilateral vesico ureteral reflux and narrowness of striated sphincter area.

The urethral pressure profile (Bohler catheter and Electromed EM K 21 cystograph) was repeated over intervals of several days and demonstrated a fluctuating urethral pressure ranging from 40 to $75 \mathrm{~cm}$ of water. However, this urethral pressure remained stable during a similar examination.

Electromyographic studies on the striated urethral sphincter showed poor 
spontaneous activity accompanied by occasional fibrillation potentials. These results were compatible with denervation. There was a moderate increase during coughing but no difference was seen with attempts at voluntary contraction of the external sphincter.

Another urodynamic study performed on 16 April 1985, coupling a water CMG (Electromed EM K 21 cystograph) with a direct and integrated EMG, revealed an increase in frequency of the potentials during abdominal pressure accompanied by slight miction which seemed to indicate a striated sphincter dyssynergia (Fig. 3).

Several pharmacological agents were evaluated. Nicergoline administered at the dose of $15 \mathrm{mg}$ and then $30 \mathrm{mg}$ had no effect. Dantrolene $(40 \mathrm{mg})$ reduced urethral pressure by $50 \%$.

The patient was discharged with a treatment regime which included a permanent indwelling catheter, a urinary antiseptic, sodium dantrolene $(100 \mathrm{mg} /$ day $)$ and nicergoline $(15 \mathrm{mg})$, even though it was ineffective during the pharmacological trial.

He was readmitted $2 \frac{1}{2}$ months later for control tests. An overall improvement was seen. The IVU demonstrated normal renal secretion starting 5 minutes after injection of contrast medium. Dilatation of the upper urinary tract had regressed, the renal calyces, renal pelvis and ureters being morphologically normal. However, the calyces were still visible after 2 hours. Cystographic films showed a rounded bladder with normal bladder walls. On micturition radiographs narrowing of the external urethral sphincter was still present. Control RUC indicated no reflux

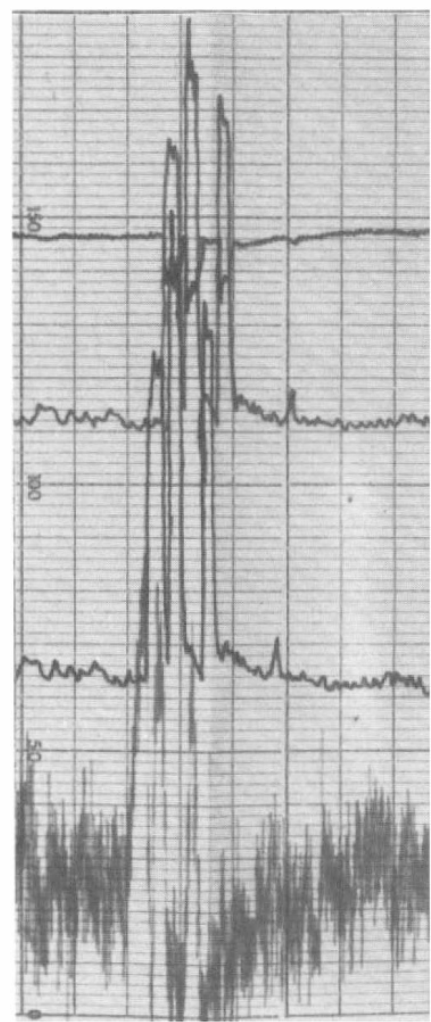
during the filling phase but it persisted above all in the left upper urinary tract on micturition radiographs.

Cystoscopy confirmed the integrity of the ureteral openings into the bladder, the absence of bladder wall hypertrophy and inflammation of the bladder mucosa. Renal function was also improved with a serum creatinine of $166 \mu \mathrm{mol} / 1$.

The urodynamic studies were identical to the previous ones (others had been performed on 10 January 1985), with a mean UP of 45 as well as persistence of a markedly increased IVP during filling. Therefore propantheline bromide $(45 \mathrm{mg} /$ day) was added to the treatment. Stimulation of the micturition reflex by rectal palpation was ineffective.

Figure 3. Urodynamic study coupling a water cystometrogram with integrated electromyography. Increase of electromyographic activity during abdominal pressure accompanied by slight miction suggestive of striated shincter dyssynergia. 
The patient was reexamined on 16 April 1985. In addition to the urodynamic studies, a water CMG coupled with EMG was performed. These results have already been presented above. Another gas CMG showed a normalisation of bladder compliance (increased to 30 ) af ter 40 days of parasympatholytic therapy. A pharmacological trial using $\mathrm{N}$-butyl-hyoscine bromide $(40 \mathrm{mg})$ further lowered the compliance.

Blood chemistry results were stationary with a serum creatinine of $164 / \mu \mathrm{mol} / 1$ and a blood urea of 5,2 mmol/1. From December 1984 to April 1985, the patient had several episodes of urinary tract inf ection with Proteus morgani, Streptococcus faecal and Serratia, all of which were treated.

\section{Conclusion}

A 48 years old man developed a vesico-ureteral reflux following spinal cord injury to the conus medullaris with an L1 compression fracture. Paraplegia was absent. However, the patient developed a neuropathic bladder complicated by renal insufficiency following a secondary tubular and interstitial nephropathy due to a severe bilateral vesico-ureteral reflux (stage 3). Urodynamic studies demonstrated probable external sphincter dyssynergia and dilated IVP during the filling phase. The vesico-ureteral reflux improved rapidly. The renal insufficiency improved more slowly af ter bladder rest (with a permanent indwelling catheter), parasympatholytic therapy and treatment of the external sphincter dyssynergia using antispastic drugs.

\section{Discussion}

It is important to remember that injuries to the spinal cord over the conus medullaris of ten show discrete or no abnormal neurological signs in the lower extremities. Absence of paraplegia does not mean that a post-traumatic isolated neuropathic bladder will not occur. The neuro-urological examination must be performed as early as possible with adequate follow up.

The possibility of an early vesico-ureteral reflux occurring during the first 6 months post-trauma has already been described (Leriche et al., 1983; Ross, 1965). Rapid alteration in renal function is also well known (Leriche et al., 1983). It is however, surprising to notice differences in tolerance of the upper urinary tract to increases of intra-vesical pressure from one case to another. In the case reported here, as in others with trauma to the conus medullaris, the early appearance of these complications can be explained by the mixed character of the injury to the bladder and sphincter area, especially of the striated urethral sphincter (Leriche et al., 1983; Ross, 1965).

The reflux mechanism is essentially due, in this case, to an abnormal increase in IVP. Structural modification of the detrusor muscle and ureteral openings into the bladder have only a secondary if not totally negligible role. Numerous authors have described the importance of increased IVP (Buzelin and Juraschek, 1981; Fellows and Silver, 1976; Leriche et al. 1983; Ross, 1965).

In this patient, we observed a permanent increase in IVP, explaining the early and rapid repercussions on the upper urinary tract. During the filling phase, IVP was already elevated, due in part to the frequent presence of a residual urine 
volume. This elevated resting pressure probably resulted largely from the spastic hypertonia rather than denervation parasympathetic hyperactivity. During voiding attempts the IVP continued to rise due to probable external sphincter dyssynergia which opposed the normal passage of urine.

Permanent bladder catheterization, which has been suspected of favouring the development of reflux, was remarkably beneficial in this particular case, both for the upper urinary tract dilatation and the reflux (Leriche et al., 1983). The results of bladder rest were improved by the administration of propantheline bromide. We would have preferred to initiate intermittent clean self catheterization combined with the latter medication but the patient was reluctant. There is no overall agreement on the benefits of this technique which should follow permanent catheterization and be associated with parasympatholytic therapy.

We chose prolonged bladder rest (several months) in order to obtain the best possible improvement for the renal insufficiency (Tarabulcy et al., 1972). During this period, it was logical to combine parasympatholytics with antispastics and even alpha-blockers such as phenoxybenzamine and moxisylyte which may be more beneficial than' nicergoline.

We hope to convince the patient of the simplicity and efficacity of selfcatheterization. At that point we will be able to complete the aetiopathogenic treatment and attempt to eliminate dysuria by using parasphincteral xylocaine infiltrations and selective S4 nerve alcoholization prior to considering endoscopic surgery, in particular a sphincterotomy which is favoured by numerous authors (Leriche et al., 1983; Tramoyeres Cases et al., 1974).

\section{Résumé}

Les auteurs rapportent l'observation d'un sévère reflux vésico-urétéral apparu frécocément au cours d'une contusion du cône médullaire avec découverte simultanée d'une insuf fisance rénale. Ils rappellent le caractère faussement rassurant de ces contusions quand elles ne s'accompagnent que d'un minimum de signes neurologiques aux membres inférieurs et qu'elles réalisent essentiellement un tableau de neurovessie post-traumatique isolée dont la prise en charge risque d'être retardée. Ils soulignent, dans la rapidité et la sévérité du retentissement rénal, le rôle du caractère souvent mixte de l'atteinte vésicosphinctérienne. Ils insistent enfin sur la responsabilité de l'hyperpression intra-vésicale, à la fois de remplissage et d'évacuation, dans la survenue de ce reflux bilatéral.

\section{Zusammenfassung}

Die Autoren berichten über die Beobachtung eines starken Blasen-Harnröhren Rückflusses der frühzeitig im Laufe einer Kontusion des medularen Kegels aufgetreten ist, mit gleichzeitiger Entdeckung einer Niereninsuffizenz. Sie erinnern an die falsch beruhigenden Merkmale dieser Kontusionen, wenn diese nur mit einem Minimum an neurologischen Symptomen der unteren Glieder begleitet sind und sie hauptsächlich das Bild einer isolierten post-trauma neuropathischen Blase darstellen, deren Betreuung möglicherweise mit Verzug vorgenommen wird. Sie unterstreichen in der Schnelligkeit und der Stärke der Nieren-Reaktion die Rolle der of t gemischten Merkmale einer Blasen-Schliessmuskel Beschädigung. Sie legen ausserdem Nachdruck auf den Einfluss des internen Úberdrucks der Harnblase, sowohl Füllung als Entleerung, beim Augtreten dieses bilateralen Rückflusses.

\section{References}

BuZELIN JM, JURASCHECK F 1981 Les complications urologiques et leur traitement in: La Paraplégie by Marc Maury. Flammarion: Paris, 334-366.

Fellows GJ, Silver JR 1976 Long-term follow-up of paraplegic patients with vesico-ureteric reflux. Paraplegia 14, 130-134. 
Leriche A, SAyag JL, Archimbaud JP 1983 Le reflux dans les neurovessies acquises de l'adulte. Aspects pronostiques et thérapeutiques à propos de 237 reflux chez 156 paraplégiques. Med. et Hyg, 41, 4181-4193.

Ross JL, CosBIE J et al. 1965 Vesico-ureteric reflux in the neurogenic bladder. British Journal of Surgery, 52, 164-167.

Tarabulcy E, Morales PA, Sullivan JF 1972 Vesicoureteric reflux in paraplegia: results of various forms of management. Paraplegia, 10, 44-49.

Tramoyeres Cases A, Walls Blasco F, Forner Valero V, Oleza Simo J 1974 La sphinctérotomie dans le traitement de la vessie neurogène du paraplégique. J. Urol. Néphrol., 80, 6, 443-464. 